\title{
Presentación al dossier Construyendo el modelo de publicación académica del sur global
}

\author{
Cecilia Rozemblum \\ Universidad Nacional de La Plata, Argentina \\ ceciroz@fahce.unlp.edu.ar \\ Arianna Becerril-García \\ Universidad Autónoma del Estado de México, México \\ arianna.becerril@gmail.com
}

En la actual configuración de la difusión internacional del conocimiento el modelo de publicación académica del sur global tiene sus propias idiosincrasias que fueron expuestas durante el 3er Congreso Internacional de Editores RedALyC, organizado conjuntamente por la Universidad Autónoma del Estado de México y la Universidad César Vallejo en Trujillo, Perú durante los días 16 al 18 de mayo de 2018.

En el transcurso de estos tres días hubo una serie de talleres, conferencias, exposiciones, posters y reuniones de editores que permitieron el intercambio de ideas, experiencias y retos futuros.

Paralelamente, el eje de las conferencias invitadas se desarrolló en torno a la idea regional de revalorizar la publicación académica del sur global. Debido a que las características propias del modelo de gestión latinoamericano no siempre suelen ser bien consideradas en algunos entornos de la comunicación científica, especialmente en el comercial, se detectó la necesidad de un esfuerzo cooperativo que impulsara la visibilidad y reconocimiento de las revistas de la región. Esta iniciativa común debía también animar a los organismos de evaluación de los países de la región a adoptar nuevos indicadores inclusivos que presenten evidencia para las políticas públicas, más allá de los indicadores tradicionales comerciales.

En esta serie de presentaciones se fueron plasmando las diversas aristas que debía contemplar una iniciativa regional. De tal modo, la intersección de los diferentes puntos de vista permitió comenzar a delinear lo que sería el esbozo de una organización internacional que permitirá aunar esfuerzos entre los editores, las instituciones y los gestores de información y aprovechar los desarrollos actuales de la plataforma RedALyC.

Los autores de estas conferencias acordaron transformar sus líneas de pensamiento en artículos científicos para que pudieran visualizarse de manera conjunta como una propuesta que más tarde se convertiría en una propuesta formal denominada AmeliCA (AmeliCA), y que sale a la luz de la comunidad científica en este Dossier titulado como el lema de ese encuentro: Construyendo el modelo de publicación académica del sur global.

En este compendio de contribuciones, que son los cimientos de una concepción de modelos sustentables y colaborativos, el lector podrá identificar los conceptos básicos que sostienen los sistemas de comunicación científica no comercial, pensada por la academia y para la academia. Aún más, este modelo no sólo considera al lector especializado sino a toda la sociedad que en su conjunto sostiene la investigación llevada a cabo en los centros nacionales y en las universidades nacionales. Por tanto, es una manera de devolver a la sociedad los que ella misma sustenta.

Introduce este dossier el reconocido académico Jean-Claude Guédon, de la Université de Montréal con la transcripción de su presentación en línea. En la misma imprime conceptos actuales y en perspectiva futura sobre la comunicación científica y sus elementos fundamentales: el artículo, las revistas y las plataformas. Continúan dos artículos de dos referentes en el apoyo al Acceso Abierto y al fortalecimiento de la comunicación científica de la región, Dominique Babini (CLACSO) y Saray Córdoba González 
(Socia honoraria de Latindex). Por su parte los integrantes de RedALyC, Eduardo Aguado-López, Arianna Becerril-García y Salvador Chávez-Ávila reflexionan sobre la edición académica desde la enriquecedora experiencia de llevar adelante uno de los proyectos más ambiciosos de revistas en Acceso Abierto de la región. Cierran este dossier, por una parte el grupo de investigación de la Universidad de Antioquia, Gabriel Vélez Cuartas, Alejandro Uribe-Tirado, Diego Restrepo-Quintero, Jaider Ochoa-Gutierrez, César Pallares, Huber Fernando Gómez-Molina, Marcela Suárez-Tamayo y Julián Calle quienes presentan sus propuestas para un modelo de medición de la ciencia desde el Sur Global basado en métricas responsables. Finalmente, los docentes e investigadores de la Universidad Nacional de La Plata, Guillermo Banzato y Cecilia Rozemblum aportan su experiencia y análisis del modelo de gestión sustentable de revistas científicas que lideran desde hace casi una década. La diversidad de países de la región representados, Canadá, México, Costa Rica, Colombia, Argentina y toda la red CLACSO, da cuenta del esfuerzo de integración de saberes, experiencias y objetivos comunes de la comunidad científica comprometida con el Acceso Abierto y conocimiento como bien común.

Es un honor poder presentar este dossier que plasma los fundamentos y necesidades de la creación de AmeliCA. Esta iniciativa está en marcha y ha generado grandes expectativas, desde su presentación oficial, en noviembre de 2018, en la segunda sesión del Foro Especial "Democratización del conocimiento académico: los desafíos del acceso abierto" de la $8^{\circ}$ Conferencia Latinoamericana y Caribeña de Ciencias Sociales. Estamos seguros que esta iniciativa traerá a la región un modelo sustentable para la reducción de brechas, aportando una nueva configuración de estrategias, en respuesta al contexto internacional, regional, nacional e institucional de la publicación académica, que busca una solución de Acceso Abierto y público, colaborativa, sostenible, protegida y no comercial para América Latina y el Sur Global. 